\title{
A Comparison of Noun and Verb Forms on the Semantic Differential
}

\author{
William Paul Livant \\ Mental Health Research Institute, University of Michigan, Ann Arbor, Michigan
}

What are the functions of formal devices in language uncovered by grammatical theory in conveying meaning? One recurring topic is the differences in meanings conveyed by noun and verb forms. Wells (1960) outlines the general philological opinion; nouns are more "static" and less "vivid" than verbs; their use makes for longer sentences but less diversity than use of verbs. Nouns also help to convey impersonality. But Wells also points out that the use of nouns or verbs entails other linguistic consequences, such as the shift from adjectival to adverbial modifiers, with a shift from the use of nouns to the use of verbs. This "prevents the contrast of nominality and verbality from being minimal." (1960, p. 216).

It would be useful to examine situations in which such a minimal contrast were experimentally created, to ascertain the effects of a noun-verb contrast on some indices of (a) denotative or (b) connotative, meaning. Brown (1957) showed, in studying denotation, that nominal and verbal labels can direct the attention of children to different features of the same visual stimulus. One way that the effects of nouns and verbs on connotative aspects of meaning may be studied is to compare the ratings of noun and verb forms of the same terms on the Semantic Differential. Such a study is suggested by the following comment of Carroll (1959, p. 72 ): "If they (the stimuli) are linguistic at all, they are always presented as nouns, noun constructions, or pronouns. . . . One wonders what sort of results would be obtained if other types of form classes were employed either as scales or as concepts." The present study is a comparison of ratings on the Semantic Differential of a sample of words which may function either as verbs or nouns without phonemic alteration.

Though this was an exploratory study, certain hypotheses were entertained: (1) Noun and verb forms will not differ on Evaluative scales. There seems to be no clear evaluative implication in the distincttion between noun and verb. (2) Verb forms will be more active than noun forms. This agrees with intuition as well as with Wells' discussion (1960). (3) Noun forms may be more potent than verb forms. Potency seems closely related to solidity and strength; it may be said to be allied to the "concrete" character of objects. (4) A mean value on each scale for the semantic aspect of each stimulus concept may be obtained by averaging the noun and verb scores. It was predicted that the more neutral this average score, the more likely will be a difference between noun and verb scores in the predicted direction. It was thought that where the affective meaning of a term is highly polarized, the differences due to grammatical form will be obscured.

\section{MeTHod}

Materials. A short form of the Semantic Differential was constructed by selecting the three scales most highly loaded on each of three factors, Evaluation, Activity and Potency, from the Thesaurus 
TABLe 1

Semantic-Differentiat. Scale Means for Noun (N) and Verb (V) Forms

\begin{tabular}{|c|c|c|c|c|c|c|c|c|c|c|}
\hline \multirow[b]{2}{*}{ Concepts } & & \multicolumn{3}{|c|}{ Evaluation } & \multicolumn{3}{|c|}{ Activity } & \multicolumn{3}{|c|}{ Potency } \\
\hline & & $\begin{array}{c}\text { good } \\
\text { bad }\end{array}$ & $\begin{array}{c}\text { beautiful } \\
\text { ugly }\end{array}$ & $\begin{array}{l}\text { positive } \\
\text { negative }\end{array}$ & $\begin{array}{c}\text { active } \\
\text { passive }\end{array}$ & $\begin{array}{l}\text { fast } \\
\text { slow }\end{array}$ & $\begin{array}{l}\text { hot } \\
\text { cold }\end{array}$ & $\begin{array}{l}\text { hard } \\
\text { soft }\end{array}$ & $\begin{array}{l}\text { masculine } \\
\text { feminine }\end{array}$ & $\begin{array}{l}\text { strong } \\
\text { weak }\end{array}$ \\
\hline \multirow[t]{2}{*}{$\mathrm{AGE}$} & $N$ & $3.8 * * * *$ & 4.0 & $3.6 * *$ & 5.3 & 4.6 & 4.1 & 4.2 & 3.8 & $3.1 *$ \\
\hline & V & 5.0 & 5.0 & 5.2 & $3.6^{* k *}$ & 4.9 & 4.5 & 3.9 & 3.9 & 4.5 \\
\hline \multirow[t]{2}{*}{ ATTACK } & $\mathrm{N}$ & 5.6 & 5.6 & 3.7 & 1.3 & 1.5 & 2.7 & 2.0 & 1.8 & 1.8 \\
\hline & $\mathrm{V}$ & 5.6 & 5.6 & 3.9 & 1.1 & 1.3 & 2.9 & 1.9 & 1.6 & 1.4 \\
\hline \multirow[t]{2}{*}{ COMMAND } & $\mathrm{N}$ & 4.1 & 4.2 & 3.1 & 2.8 & 3.4 & 4.0 & 2.4 & 2.3 & 2.4 \\
\hline & $\mathrm{V}$ & 4.3 & 4.3 & 3.4 & 2.8 & $2.8^{* / 3}$ & 3.7 & 2.4 & 2.0 & 2.1 \\
\hline \multirow[t]{2}{*}{ DREAM } & $\mathrm{N}$ & 3.4 & 3.4 & 3.6 & 3.6 & 4.1 & 3.2 & 4.5 & 4.8 & 3.7 \\
\hline & $\mathrm{V}$ & 3.1 & 3.1 & 3.8 & 3.4 & 4.0 & 3.6 & 5.0 & 4.5 & 3.7 \\
\hline \multirow[t]{2}{*}{ DOUBT } & $\mathrm{N}$ & 4.3 & 5.1 & 5.2 & 3.6 & 5.0 & 4.6 & 3.4 & 4.2 & 3.7 \\
\hline & $\mathrm{V}$ & 4.3 & 4.8 & 5.0 & 3.2 & 4.3 & 4.1 & 3.7 & 3.9 & 3.1 \\
\hline \multirow[t]{2}{*}{ FEAR } & $\mathrm{N}$ & 5.3 & 6.2 & 5.1 & 3.0 & 2.9 & 4.7 & 2.9 & $4.1 *$ & $2.9 *$ \\
\hline & $\mathrm{V}$ & 5.6 & 5.9 & 4.9 & 3.0 & 2.8 & 4.1 & 3.4 & 4.9 & 3.5 \\
\hline \multirow[t]{2}{*}{ LOVE } & $\mathrm{N}$ & 1.7 & 1.7 & 1.8 & 3.1 & 4.1 & 2.2 & $5.0 *$ & 4.4 & 1.8 \\
\hline & $\mathrm{V}$ & 1.6 & 1.6 & 1.6 & $1.8 * * *$ & $3.2 *$ & $1.7 * *$ & 5.4 & 4.3 & $1.4^{*}$ \\
\hline \multirow[t]{2}{*}{ PLAN } & $\mathrm{N}$ & 2.9 & 3.3 & 2.7 & 3.3 & 4.3 & 3.8 & 3.4 & 3.5 & 3.1 \\
\hline & $\mathrm{V}$ & 2.3 & 3.5 & $2.1 *$ & $1.8^{* * *}$ & 3.7 & 3.8 & 3.2 & 3.6 & $2.3 * * *$ \\
\hline \multirow[t]{2}{*}{ WANT } & $\mathrm{N}$ & 4.4 & 4.6 & 3.4 & 4.7 & 3.6 & 3.6 & 3.3 & 4.3 & 2.5 \\
\hline & $\mathrm{V}$ & 4.4 & 4.2 & 3.2 & $3.8^{* *}$ & 3.1 & $3.0^{* *}$ & 3.3 & 3.9 & 2.3 \\
\hline \multirow[t]{2}{*}{ TAEJ } & $N$ & 3.9 & $3.9^{*}$ & 3.6 & 3.7 & 3.8 & 3.5 & 3.9 & 3.7 & 3.4 \\
\hline & V & 4.2 & 4.5 & 3.3 & $2.7 * *$ & $3.1^{*}$ & 3.4 & 3.9 & 3.7 & 3.6 \\
\hline \multirow[t]{2}{*}{ THOOP } & $\mathrm{N}$ & 4.4 & 5.2 & 4.1 & 3.9 & 3.9 & 4.4 & $3.2 * * *$ & 3.5 & 3.7 \\
\hline & $\mathrm{V}$ & 4.3 & 4.9 & 3.9 & 4.1 & 3.6 & 4.3 & 4.9 & 3.3 & 3.5 \\
\hline "NOUN" & & 3.4 & 3.4 & 2.9 & 5.3 & 5.2 & 4.5 & 3.6 & 3.7 & 3.2 \\
\hline "VERB" & & 3.6 & 3.7 & 2.6 & $1.9 * * *$ & $2.4 * * *$ & $3.2 * *$ & $2.3 * *$ & 3.4 & $2.0^{* * * * *}$ \\
\hline
\end{tabular}

* $P<.05 . \quad$ ** $P<.02 . \quad * * * P<.01$.

Study in Osgood, Suci, and Tannenbaum (1957). These were as follows.

Evaluation: (1) good-bad, (2) beautiful-ugly, (3) positive-negative;

Activity: (1) active-passive, (2) fast-slow, (3) hot-cold;

Potency: (1) hard-soft, (2) masculine-feminine, (3) strong-weak.

On the rating form, the order of scales was randomized and the position of every other pair of adjectives was reversed.

The stimuli were of three kinds. (a) Nine words were selected which may occur as noun or verb without phonemic alteration, and which would span a wide range or each semantic dimension. These words were: AGE ATTACK COMMAND DREAM DOUBT FEAR LOVE PLAN WANT. (b) Two nonsense syllables were presented as words in an unknown foreign language. They were TAEJ and THOOP. Each of these eleven syllables were presented orally as a noun in the form "a..." or "an ..." and as a verbal infinitive in the form "to ..." (c) Finally the terms NOUN and VERB were presented for rating.

Procedure. General instructions for the Semantic Differential were given as in Osgood, Suci, and Tannenbaum (1957). Following this the experimenter stated: "Now I will state a word which may occur as a verb or a noun. I would like you to think of this word the way you might use it as a verb and rate it on all nine scales using the letter $V$. Likewise I would like you to think of this word the way you might use it as a noun and rate it on all nine scales with the letter $N$. Please try to make your rating for both noun and verb on each scale before going on to the next scale. The first word is AGE. Imagine it as a verb, 'to age.' Imagine it as a noun, 'age,' 'an age.' Now please rate both the verb and the noun on all scales."

For the two nonsense syllables, it was explained that they were words in Vietnamese. The $S$ s were asked to imagine each as a noun and a verb, although they did not know their meanings. Finally, 
TABLE 2

SUMmary OF VERB-NOUN COMPARISONS

\begin{tabular}{lccc}
\hline & Evaluation & Activity & Potency \\
\hline Verb more positive than Noun & $20(2)^{*}$ & $30(13)$ & $19(5)$ \\
Verb equals Noun & 1 & 0 & 1 \\
Noun more positive than Verb & $15(2)$ & $6(0)$ & $16(4)$ \\
\hline
\end{tabular}

* Number of significant comparisons are given in parentheses.

subjects were asked to rate simultaneously the English words NOUN and VERB.

All $S$ s received the words in alphabetical order, then the nonsense syllables and finally the pair NOUN and VERB. Twenty-one college students were run in groups of three.

\section{Results}

Table 1 shows all means based on an $N$ of 21, together with an indication of significant differences between pairs of Noun and Verb forms. All scores fall on a seven-point scale. A low number indicates positive rating, a high number indicates negative rating. The significance test in each case was a $t$-test between correlated scores. In Table 1 there are 108 comparisons of noun and verb forms, 36 on each factor. Table 2 summarizes the direction of these comparisons (numbers of significant comparisons are given in parentheses).

Only the Activity dimension shows a difference; furthermore, only on Activity do all the significant comparisons go in the same direction. Hypotheses (1) and (2) are sustained; hypothesis (3) is rejected. Hypothesis (4) predicts that significant differences between noun and verb forms should occur for concepts whose mean ratings are close to neutral, whereas for concepts whose mean ratings are highly polarized the effects of grammatical differences should be masked. To test Hypothesis (4) all comparisions were divided into significant and nonsignificant classes based on Table 1. The mean value of noun and verb score was computed for each comparison, and its absolute deviation from the neutral point was taken. The mean devia- tion from neutral point was .83 for the significant comparisions, and .80 for the nonsignificant ones. This difference is itself not significant; Hypothesis (4) is therefore rejected.

\section{Discussion}

It appears that certain connotative differences of a minimal noun-verb contrast, when both forms are phonologically identical, are reflected in the semantic differential, primarily in Activity. This conclusion must be qualified in view of the method employed, that of forced comparison, in which noun and verb form were rated on each scale before proceeding to the next scale. Forced comparison may tend to emphasize the noun-verb contrast; in addition it may emphasize denotative aspects of the concepts rated.

An extensive study of Carroll (1960) agrees with the present result on Evaluation. None of forty objective measures of prose style, including proportions of several kinds of nouns and verbs in text, had significant evaluative loadings. Only ratings on judgmental scales similar to the ones on the semantic differential had significant loadings on Evaluation. As Carroll (1960, p. 289) remarks: "It is cheering to note that not a single objective measure shows any significant loading on factor A, General Stylistic Evaluation. Although the style of literary passages can be indexed in certain ways mechanically, it cannot be evaluated mechanically."

It appears now to the writer that the General Semantic Differential is of very limited usefulness in detecting connotative differences which are functions of grammatical differences. There appears to be very great concept- 
scale interaction in any use of the semantic differential, and that for each substantive area a differential with appropriate dimensions must be developed. Indeed, most recently Osgood explicitly disclaims that anything like The Semantic Differential exists (1962). Carroll's study (1960) represents the first attempt to construct a differential appropriate to the domain of English written style. His factor analysis of prose passages yielded six factors: General Stylistic Evaluation, Personal Affect, Ornamentation, Abstractness, Seriousness, and Characterization. The measures defining such factors ought to be used on future studies of minimal contrast.

\section{REFERENCES}

BRown, R. W. Linguistic determinism and part of speech. J. abnorm. soc. Psychol., 1957, 55, 1-5.

Carroll, J. B. Review of Osgood, Suci, and Tannenbaum: The measurement of meaning. Language, 1959, 35, 58-76.

Carroll, J. B. Vectors of prose style. In T. A. Sebeok (Ed.) Style in language. New York: Wiley, 1960. Pp. 283-92.

OsGood, C. E. Studies on the generality of affective meaning systems. Am. Psychol., 1962, 17, 11-28.

Osgood, C. E., Suci, G. J., and Tannenbaum, P. H. The measurement of meaning. Urbana: Univer. of Illinois Press, 1957.

WeLLS, R. Nominal and verbal style. In T. A. Sebeok (Ed.) Style in language. New York: Wiley, 1960. Pp. 213-20.

(Received September 10, 1962) 